\title{
"Smuggling in Accidental Poetry": Cognitive and Stylistic Strategies of a Stammering Teen in David Mitchell's Black Swan Green
}

Constance Robert-Murail, Université Gustave Eiffel - Paris-Est (France)

\section{Extract 1}

Miss Throckmorton'd been playing Hangman on the blackboard one afternoon with sunlight streaming in. On the blackboard was

NIGH-ING- -E

Any duh-brain could work that out, so I put up my hand. Miss Throckmorton said, "Yes, Jason?" and that was when my life divided itself into Before Hangman and After Hangman. The word "nightingale" kaboomed in my skull but it just wouldn't come out. The $n$ got out okay, but the harder I forced the rest, the tighter the noose got. I remember Lucy Sneads whispering to Angela Bullock, stifling giggles. I remember Robin South staring at this bizarre sight. I'd've done the same if it hadn't been me. When a stammerer stammers their eyeballs pop out, they go trembly-red like an evenly matched arm wrestler, and their mouth guppergupperguppers like a fish in a net. It must be quite a funny sight.

It wasn't funny for me, though. Miss Throckmorton was waiting. Every kid in the classroom was waiting. Every crow and every spider in Black Swan Green was waiting. Every cloud, every car on every motorway, even Mrs. Thatcher in the House of Commons'd frozen, listening, watching, thinking, What's wrong with Jason Taylor?

But no matter how shocked, scared, breathless, ashamed I was, no matter how much of a total flid I looked, no matter how much I hated myself for not being able to say a simple word in my own language, I couldn't say "nightingale." In the end I had to say, 'I'm not sure, miss,' and Miss Throckmorton said, 'I see.' She did see, too. She phoned my mum that evening and one week later I was taken to see Mrs. de Roo, the speech therapist at Malvern Link Clinic. That was five years ago. 
It must've been around then (maybe that same afternoon) that my stammer took on the appearance of a hangman. Pink lips, broken nose, rhino cheeks, red eyes 'cause he never sleeps. I imagine him in the baby room at Preston Hospital playing eeny, meeny, miney, mo. I imagine him tapping my koochy lips, murmuring down at me, Mine. But it's his hands, not his face, that I really feel him by. His snaky fingers that sink inside my tongue and squeeze my windpipe so nothing'll work.

(Mitchell 2007 [2006]: 26) ${ }^{1}$

\section{Extract 2}

'Why d'you' - Hangman blocked 'nick,' then 'steal,' so I had to use the naff 'pinch' 'pinch the fags?' [...]

'Plebs smoke "fags." I smoke cigarettes. I don't "pinch." Plebs "pinch." I "liberate."

'Then why did you "liberate" the -' (Now I couldn't say 'cigarettes.')

'Ye-es?' prompted Hugo.

'The Lambert and Butlers.'

'Ifyou mean "Why did you liberate the cigarettes?", it's because smoking is a simple pleasure, with no proven side effects except lung cancer and heart disease. I intend to be long dead by then. If you mean, "Why choose Lambert and Butlers in particular?", it's because I wouldn't be seen homeless smoking anything else, except for Passing Cloud.'

(Mitchell 2007 [2006]: 62-63)

\section{Introduction: the power of a single voice}

When thinking of the words "powerful literary fiction" and "David Mitchell", the first book that comes to mind is his magnum opus, the extremely ambitious and intricate Cloud Atlas (2004), adapted for the screens by the Wachowski sisters and Tom Tykwer in 2012 (Tykwer et al. 2012). The book interweaves six narratives over almost six hundred pages, spanning multiple centuries and continents, each told in a different voice, which has led a New York Times article to review it as "a doggedly expert gloss on various writers and modes"

1 In the following, all quotations without any reference specified are taken from this literary excerpt. 
(Bissell 2004: n. p.). Only two years later, Mitchell published a homely semiautobiographical novel, Black Swan Green (2006), chronicling the life of Jason Taylor, a 13-year-old growing up in the backwater town that gives the novel its title. I was quite intrigued the day I realised that this work of fiction, which in many ways could or should have been Mitchell's debut novel, was written after the dazzling puzzle of a book that is Cloud Atlas. In comparison with the latter's vast project, the book presents a single year divided into 13 chapters, each corresponding to a month between January 1982 and January 1983, and is set in a tiny perimeter of a few kilometres around Jason's house, in the Worcestershire countryside. Each chapter is sufficiently independent that Black Swan Green sometimes reads like a collection of short stories. Throughout the story, Jason navigates problems at school, where he is bullied, and at home, where his parents' marriage is falling apart. The reader witnesses Jason mediating between the various personae of his fragmented identity: Unborn Twin, an alter ego who is allegedly responsible for most of his bad decisions; Eliot Bolivar, the nom-de-plume he uses to anonymously publish poems in the local parish newspaper; and last but not least, Hangman, the evil personification of his stammer.

After having created a world-encompassing sextet in Cloud Atlas, Mitchell bets on the creative power of a single voice, that of a young boy with a sharp wit and a twisted tongue. Using several close readings of the novel and elements pertaining to the cognitive psychology of stuttering, I will explore the powerful tension between communication and cognition in Black Swan Green. Indeed, the novel materialises the relation of psyche and voice in Jason's stutter, creating verbal accidents in the narrative that elicit physical and intellectual empathy in the reader. I will focus mostly on a pivotal moment at the beginning of "hangman", the second chapter of the novel. This scene is a highdefinition rendition of the few seconds during which an eight-year old Jason tries to give the correct answer to his teacher in class, only to find himself smothered by an ominous presence - his newfound speech impediment. In the second extract, taken from the following chapter, thirteen-year old Jason timidly tries to understand what prompted his older, shrewder cousin Hugo to steal cigarettes from the local drugstore. This will illustrate Mitchell's astute treatment of the stutter in dialogue. Even if the written nature of this paper does not allow me to sound Mitchell's prose, I invite you to read the extracts aloud and stumble over it yourself, letting the words challenge your personal voice and physicality. 
I would argue that these extracts present many characteristics that bring about a strong form of empathy in the reader, at once intellectualised and physical. Michael Toolan's study of "high emotional intensity passages" shows that "readers [...] respond not so much in empathy with characters experiencing acute physical pain or pleasure but rather with ones presented experiencing complex revised understandings of their embedded situation" (Toolan 2012: 213). In the first extract, speaking five years after the fact but still enduring the consequences of a key moment in his autobiography, Jason's revised understanding of his experience of stammering is both complex enough to appeal to an adult reader and youthful enough to let us enjoy the voice of a sassy 1980 s teenager. Both texts form a complex cognitive and physical exploration of a specific communicative impairment but also of a young mind in active, dynamic development. Firstly, I will examine the visual and cognitive characterisation of Jason's disorder. The second part of this article will focus on the poetic implications of Jason's (and David Mitchell's) stutter, as well as its role in the physical involvement of the reader.

\section{2. "What's wrong with Jason Taylor?"}

What is so funny about stuttering? Its representation in the arts has mostly been used for comic relief, most notably through theatrical tradition - in the commedia dell'arte, Tartaglia (literally, 'The Stutterer') is a stammering old fool always lost in his poetry. In the past decades, there has been movement towards multidimensional, non-stereotypical depictions of characters with physical or mental disabilities, as highlighted in Jeffrey K. Johnson in his very exhaustive chapter "The Visualization of the Twisted Tongue: Portrayals of Stuttering in Film, Television, and Comic Books" (Johnson 2008). Yet he adds that within this movement, stuttering remains "a crude formulaic storytelling device that adheres to basic misconceptions about the condition" (ibid.: 246). More recently, Judith Maginnis Kuster underlined the main three negative stereotypes around stuttering in films and television, namely: people who stutter can't handle a crisis; stuttering is comical or something to mock; stuttering is a symptom of a psychological flaw or the sign of an evil person (see Kuster 2011). These tropes have been intensely internalised by Black Swan Green's young protagonist, who projects his fear of being either a coward or a monster onto his alter egos Unborn Twin and Hangman. In this extract, 
Mitchell attempts to portray stuttering as both an internal process and an external demonstration, creating a tension between trauma and self-mockery.

\subsection{Visualising cognitive treatment}

Sight is central to the structure of the first extract. It starts off with a seemingly harmless setting, sunlight streaming into a classroom, although the presence of the Hangman is already unsettling. The second part of the first paragraph forms the knot of the scene, reproducing the tight noose that strangles Jason. It shifts the focus from Jason's physical experience to his classmates' reactions to an impersonal, general depiction of what a stammerer looks like. We can see how Jason is swiftly disconnecting from his own body to experience the moment from the outside. In the second paragraph, the repetition of "waiting" (\$2) accompanies a highly cinematographic progression: we're zooming out from the classroom to a bird's eye view of the village to a national scale, only to zoom back in on Margaret Thatcher herself, over a few very long seconds, suspended between silence and speech. In the third paragraph, the few seconds of silence lead to a torrent of words as Jason analyses his own feelings and puts an end to the excruciating scene. To be seen, however, is also to be understood, to be diagnosed, to be treated, as his teacher sees that Jason needs help ("[...] and Miss Throckmorton said, 'I see.' She did see, too." [\$3]) and reaches out to his mother behind his back. Finally, the last paragraph presents the reader with a graphic personification of the teenager's speech impediment, as if to exorcise an unwanted evil presence. The chilling image of Hangman will stick with the reader as it hangs over Jason throughout the book.

By the end of the extract, Jason's teacher has externalised the problem out of the classroom and into a therapist office by treating it as a medical condition, an affection that changes Jason's public persona. Jason, on the other end, has internalised his issue by creating a new private persona, which still enables him to treat the stammer as external, otherly. The stammer sends Jason into the margins, away from what is "normal" in society but also away from his "normal" self.

In this scene, the repetition of the word "sight" "bizarre sight" and "funny sight”, \$1) refers to Jason's teenage obsession with how he is perceived by others. In Black Swan Green, Jason looks at himself speak as much as he hears himself speak. The repeated verb "remember" $(\$ 1)$, far from referring to a personal feeling, portrays the reaction of a third-party and is immediately fol- 
lowed by a description of Jason from an external perspective. Mark Onslow explains that many people who stammer experience social phobia that leads to "observer perspective" memories: "When most people are asked to recall a social encounter, they will relate to their own field of vision - their field perspective - which is of course what is appropriate for them to recall. However, those affected with social anxiety disorder (...) are known to report an observer perspective" (Onslow 2016: 226).

People reporting this explain that their memories of stressful interactions look like they were filmed from behind their shoulder: they see themselves in third-person. It is of course the product of an a posteriori reconstruction, which underlines how anxiety shifts the focus. The observer perspective is often linked to traumatic situations, as it creates some distance between oneself and the event to pretend that it happened to someone else. This detached memory, however, tends to create discontinuity in self-representation. In spite of Jason's attempts to create distance, the extract presents the event as a turning point in his life: "life divided itself into Before Hangman and After Hangman"(\$1). This is consistent with what Mark Onslow has witnessed in young patients: a stammer can appear abruptly in a child's speech, over the course of a day or a week (Onslow 2020: 62). The seemingly factual statement "That was five years ago" $(\$ 3)$ could imply that the narrator has long moved on from this childhood scene, but instead it highlights how vivid the memory, and the shame associated to it, really are.

\subsection{Acting Invisible}

Jason's deadpan sense of humour and taste for hyperbole are another attempt at deflecting the dramatic tension of the extract. Self-mockery allows him to put some distance between himself and the event, but some of his derogatory comments hide something darker. "Total flid" (\$3), as he calls himself, is an extremely offensive way to describe someone mentally or physically handicapped. It is a shortened version of thalidomide, a drug that caused birth defects, and which here expresses the protagonist's own anxiety at being a disappointment to his family. Even if it is never said explicitly, the reader can examine the timeline of the book and deduce that the onset of Jason's speech impediment corresponds to the same year his father started an extramarital affair, which will result in his parents' divorce by the end of Black Swan Green. The source of the stammer was traditionally defined by pathologists, such as 
Wendell Johnson, as a psychological or emotional problem, or a projection of parental anxieties onto the child (Johnson 1959).

Jason links his problems with his speech, with his schoolmates and with his parents together by putting himself into some sort of Venn diagram ${ }^{2}$. He expresses his fear of being seen or stared at as threefold: "Picked-on kids act invisible to reduce the chances of being noticed and picked on. Stammerers act invisible to reduce the chances of being made to say something we can't. Kids whose parents argue act invisible in case we trigger another skirmish. The Triple Invisible Boy, that's Jason Taylor" (233-234).

The emphasis on vision in this extract is not only a way to process trauma through observer perspective memory: it also betrays Jason's fear of standing out.

\subsection{An idiosyncratic disorder}

According to Mark Onslow, "stuttering is an idiosyncratic disorder" (Onslow 2020: 11) in that it forces each individual to create self-management strategies. Speaking rhythmically, for instance, also known as syllable-timed speech (STS), has been known for centuries to be a fluency-inducing condition for people who stutter. Jason is taught this strategy by his speech therapist, and sing-songy rhythms pervade the textual space: "Pink lips, broken nose, rhino cheeks, red eyes "cause he never sleeps" (\$4). This nightmare-like vision of Hangman paradoxically sounds like a nursery rhyme. This familiar rhythm then may evoke in the reader's mind memories of fairy godmothers leaning over baby cradles, granting them powers or cursing them for life. The oral, repetitive and musical dimension of the sentences, small moments of accidental poetry occurring within the prose, elicit empathy from the adult reader, who is at once reminded of the childish innocence of the narrator.

Stammering is not only a matter of not being able to express oneself, it is also a form of physical expression in itself. Onslow notes that what he calls "nonverbal superfluous behaviours" (Onslow 2020: 11) are the most idiosyn-

2 Popularised by English logician John Venn in the 1880s, Venn diagrams are visual diagrams showing the logical relation between sets, usually represented by intersecting circles or ellipses. Here, Jason's invisibility is placed at the intersection of three sets of interpersonal issues: school bullying, instability in the household, and a medical condition impacting self-expression—each of them interacting in a specific way. 
cratic features of a person who stammers, varying from person to person. Onslow's characterisation resembles an accidental choreography:

They include compressed lips, open mouth, breath holding, blinking, nostril dilating, eyebrow raising, grimacing, facial, head and torso movements, inspiratory airflow, runts and other inappropriate noises, and aberrant fluctuations in pitch and loudness. (ibid.)

One of Jason's classmates finds herself "stifling giggles" (\$1): she is able to suppress her laughter, making Jason's lack of control even more striking. This idea of stifling oneself also highlights the importance of air flow in stuttering. Various parts of the body are engaged in this experience. Words "kaboom" in Jason's skull, his eyes pop out as he gasps for air like a fish out of water, and his stammer is like a hand plunging down his windpipe (see \$1). Jason is well aware of the multimodal possibilities of language, as he jokes a few pages later: "At this rate I'm going to have to learn sign language" (32).

People who stutter say on average around one third less than those who do not (Onslow 2016: 15). This rarefied speech also induces idiosyncratic methods of expressing oneself. Behind Jason's reduced verbal output, his mind is going a mile a minute to get himself out of difficult situations. Throughout the book, the reader witnesses him on the lookout for problematic letters and difficult words that might come up in conversation, avoiding them through circumlocutions, restricting his grammar to less elaborate clause constructions, and rarer expressions of modality. My second extract from chapter 3 illustrates quite smoothly Jason's strategies and Mitchell's treatment of dialogue. Here, Jason is facing his older, cooler, stronger cousin Hugo, and struggles to ask him why he felt the need to steal some cigarettes from the local shop:

'Why d'you' - Hangman blocked 'nick,' then 'steal,' so I had to use the naff 'pinch' - 'pinch the fags?' (...)

'Plebs smoke "fags." I smoke cigarettes. I don't "pinch." Plebs "pinch." I "liberate."'

'Then why did you "liberate" the - ' (Now I couldn't say 'cigarettes.')

'Ye-es?' prompted Hugo.

'The Lambert and Butlers.'

'If you mean "Why did you liberate the cigarettes?", it's because smoking is a simple pleasure, with no proven side effects except lung cancer and heart disease. I intend to be long dead by then. If you mean, "Why choose Lambert 
and Butlers in particular?", it's because I wouldn't be seen homeless smoking anything else, except for Passing Cloud.' (Mitchell, 2007 [2006], 62-63)

In this short dialogue, word avoidance leads to constant reconstruction of speech, at first through a play on synonyms and language registers. Jason wants to use the colloquial "nick" to sound cool and detached ('nick' as a noun is also UK slang for prison, adding a rebellious touch to the word). He pivots towards the more neutral "steal", but in the end can only utter "pinch", which sounds very "1980s surfer" (Urban Dictionary 2021), but definitely uncool according to our thirteen year-old hero. The second tactic consists in switching an superordinate for its hyponym, as when he goes for the specific brand Lambert and Butlers because he cannot utter the umbrella term 'cigarettes'. In contrast, Hugo appears to be in total control of his speech, using Jason's choice of words against him and elaborating verbose, uninterrupted explanations. Each of Jason's lexical choices is dissected and disqualified, then re-labelled accordingly to Hugo's vision. He goes as far as providing two different interpretations for Jason's questions. The overanalysis that follows is comically excruciating, as the reader is well-aware that Jason just went with the only words that would come out. His malicious cousin is probably aware of that, too. He's both actor and director of the scene - the verb "prompt" even explicitly states his role as a theatrical prompter, suggesting to Jason his forgotten line.

When they are at work in Jason's negotiation of dialogues, his palliative linguistic devices seep into every aspect of the narrative. They add rhythms and textured sounds to his storytelling. Indeed, in our extract, rephrasing and looking for synonyms are an integral part of how to process emotions: "But no matter how shocked, scared, breathless, ashamed I was, no matter how much of a total flid I looked, no matter how much I hated myself for not being able to say a simple word in my own language, I couldn't say 'nightingale'”(\$3). Jason scours words as if literally running through the pages of a dictionary, each adjective both necessary and insufficient to describe his feelings. The repetition of "no matter" connects three verbs and three levels of understanding the event: Jason's immediate mental state ("I was"), his outward appearance ("I looked") and the inward pull of self-hatred ("I hated myself"). The entire sentence is in itself a delaying tactic, rushing in towards the final utterance of the word that cannot be pronounced: "nightingale" $\left(\$_{3}\right)$. It is the bird of poets, no less: the bird of Cowper, Milton, Coleridge and Wordsworth, the symbol of an eloquence that seems out of reach for our young hero. In Ovid's Metamor- 
phoses, Philomela is raped by Tereus who then cuts out her tongue in punishment for her defiant manner of speech. She nonetheless weaves a tapestry to tell her story and gets her revenge on Tereus. The gods finally turn her into a nightingale so that she can escape Tereus's wrath. The song of a nightingale is therefore also associated with a mournful lament, with Philomela's voicelessness and the speech impediment caused by her injuries. This intertextuality with English Romanticism and Roman narrative poetry points to the extract's emphasis on emotions experienced through the body on the one hand, and on voice and performance on the other.

\section{3. "Accidental poetry"}

\subsection{A voice for the voiceless?}

I chose this extract because it is highly representative of Mitchell's stylistic treatment of a communicative impairment he knows well, as he suffers from stammering himself. He defined Black Swan Green as a way of "outing" himself regarding his speech defect (Mitchell 2011). Mitchell has also been vocal about his son's nonverbal autism. He and his wife have translated The Reason I Jump, a memoir written by Naoki Higashida, then not much older than Jason, about his nonverbal form of autism (Higashida 2013). In a review of the book aptly entitled "Voice for the Voiceless", Sallie Tisdale notes: "Mitchell writes that reading 'The Reason I Jump,' he 'felt as if, for the first time, our own son was talking to us about what was happening inside his head"' (Tisdale 2013: n. p.), which is incidentally (or accidentally) similar to what we are confronted to in this extract from Black Swan Green.

In an interview for The Guardian a few years ago, Mitchell added: "So what are we still getting wrong about autism, and how do we get it right? [...] First up, is that we stop assuming a communicative impairment denotes a cognitive one." (Mitchell 2017: n. p., emphasis added) The book as a whole, and this passage in particular, puts in sharp focus the discrepancy between Jason's communicative difficulties and his extremely articulate, vivid interior monologue. The reader is caught between Jason's frustration at not being able to express himself, and delectation in the many ways he finds to express himself nonetheless.

This passage is powerful in the way it displays a moment of weakness, and challenges the power mechanisms within and through discourse. Ever since the Greek conception of logos, organised speech and rational thought have 
been considered two sides of the same coin. Eloquence is not just a matter of speaking, but of who has the right to speak - the proficient orator has a hold on discursive power, as we have seen in the short dialogue between Jason and Hugo. Books such as Black Swan Green and The Reason I Jump are respectively fictional and non-fictional attempts to counterbalance a lack of positive cultural representations of disorders such as aphasia or stuttering, giving them visibility within the public sphere and, quite literally, a voice. In interviews, Mitchell mentions that he treats his stammer and other people's reactions to it with a form of "militant indifference" (Mitchell 2011: n. p.), which is, in its own way, a political stance.

\subsection{The birth of a novelist}

Jason's voice elicits tenderness and empathy within the reader, and underlines one of the key strengths of Black Swan Green - the youthful creativity and accidental poetry of Jason's language. According to David Mitchell, the power of the novel relies on a delicate balance:

I wanted Jason to be unformed enough to be plausible — I didn't want him to speak like a child genius - but interesting enough to be readable. That's tough, but there's one thing on your side. Kids that age don't have the linguistic formulas in place that adults do - what linguists call collocation the way certain words go with certain other words. That means you can smuggle in accidental poetry, and, with luck, wisdom and insight too. (Mudge 2006, emphasis added)

The Latin root "accidens" can mean occurrence, chance or misfortune. Jason's verbal mishaps are presented in the novel as a form of pharmakôn, both poison and cure, cause of his social anxiety and source of his poetic creativity. An accidental, in music, is also "a note foreign to a key indicated by a signature" (Merriam-Webster online dictionary 2021). Mitchell inoculates prose with the accidental, foreign musicality of stuttering. Accidental poetry also occurs with outbreaks of childish artlessness in the narrative. The novel teems with tongue-in-cheek and somewhat laboured nods to 80s British pop culture. Inside this network of references, another smaller, more intimate network is created with Jason's childlike habit of being extremely precise with proper nouns, e.g. in our extract, "Malvern Link Clinic" (\$3) and "Preston Hospital" (\$4), as well as full names of classmates, hyperlocal details that the reader (just like the adults in Jason's life) most likely does not care about and 
will not remember. This is but one of many features Mitchell has used in his novel to aim at the reader's willing suspension of disbelief and shape an unformed, plausible narrator. As he also notes in an article in The Telegraph entitled "Let me speak": "Children compensate for a lack of lexicon with simile or metaphor" (Mitchell 2006: n. p.). Jason tends to rely on comparisons in moments of crisis, whether they are safely commonplace ("like a fish in a net" [\$1]) or more colourful ("like an evenly matched arm wrestler" [\$1]).

Jason's favourite palliative strategy is poetic writing, as he notes: "Only in my poems, I realised, do I get to say exactly what I want" (156). Mrs. de Crommelynck, a strange old lady who has read his writings in the local parish newspaper, tells him: "The poem is a raid on the inarticulate" (147). This is a direct nod to T.S. Eliot's own take on the failure of speech as standard for poetic creation:

[...] Trying to use words, and every attempt

Is a wholly new start, and a different kind of failure

Because one has only learnt to get the better of words

For the thing one no longer has to say, or the way in which

One is no longer disposed to say it. And so each venture

Is a new beginning, a raid on the inarticulate

With shabby equipment always deteriorating

In the general mess of imprecision of feeling,

Undisciplined squads of emotion. [...] (Eliot 1943, "East Coker", V)

Eliot's "shabby equipment", "general mess of imprecision of feeling" and "undisciplined squads of emotion" unintentionally summarise the adolescent experience of moving around the world in a body that feels increasingly foreign and inadequate, filled with new urges and half-formed thoughts.

Yet, Black Swan Green does not show the reader a single poem Jason has written. This feels very intentional. The only extract that Jason writes diegetically is actually in prose: on page 261 (in the penultimate chapter "disco"), the first two sentences of the chapter that precedes it ("goose fair") are reproduced in what is supposed to be Jason's handwriting, suggesting he has begun to write what will become Black Swan Green. At the end of the book, Jason admits to his sister that he has stopped writing poems. We are made to consider that poetry was, for him, a transitional activity of early adolescence. As he grows up, he starts writing prose. Entering a new phase of his development, leaving childhood behind, the poet becomes a novelist. David Mitchell notes that not all stammerers become writers and not all writers are stam- 
merers (Begley 2010). But in interviews and articles he has repeatedly argued that the type of prose writer that he became owes much to his speech defect and the strategies he implemented to avoid being seen as a stammerer:

Your stammer informs your relationship with language and enriches it, if only because you need more structures and vocabulary at your command. Quite probably, if I could have produced unbroken, effortless sentences like my secretly envied classmates, I would never have felt the need to write them down, nor become a writer. (Mitchell, 2006: n. p.)

The specificities of Mitchell's and Jason's storytelling are underlined by Garan Holcombe:

[Jason] must, if he is to conceal his speech defect, forever seek alternative means of saying the same thing; he must rephrase, search for synonym and close association. He must also think ahead so as to avoid being surprised by words beginning with certain letters (...) It is little surprise, then, that the adult novelist should display such polyphonic narrative virtuosity, or that he should be interested in retelling stories from different perspectives, or that he should display such sensitivity toward the formal necessity of coherence and structure. (Holcombe 2013: n. p., emphasis added)

In a way, Mitchell shows in Black Swan Green what he needed to go through to one day be the author of Cloud Atlas. We can thus read it as an autobiographical Künstlerroman, in which stylistic practices articulate themselves around an articulatory deficiency. The daily work of commutation and permutation, as well as the ceaseless struggle of anticipating and restructuring his discourse, would be in a way the starting point of the author's idiosyncratic writing, the first faltering steps of a stammering writer. This extract illustrates that powerful prose can be achieved by treating language as a permanent process growing organically in all directions at once, which is what Deleuze beautifully states in his text He Stuttered: "Creative stuttering is what makes language grow from the middle, like grass; it is what makes language a rhizome instead of a tree, what puts language in a state of perpetual disequilibrium" (Deleuze 1994: 27). Teetering on the brink of silence, balancing off one sentence with the next, Mitchell's young narrator grasps ten words at a time as he gasps for air. 


\subsection{Multimodality, empathy and somesthetic sensations}

I have shown in our first extract the focus on vision, which goes hand in hand with a depiction of the gestuality, the multimodality of language. I will now conclude on another 'accident' at work here, involving the reader's body. In this very specific sentence the repetitions and muffled sounds force the reader himself/herself to stumble on words: "When a stammerer stammers their eyeballs pop out, they go trembly-red like an evenly matched arm wrestler, and their mouth guppergupperguppers like a fish in a net" ( $\$ 1$, emphasis added). Here, the back and forth of the tongue and mouth between the bilabial nasal $/ \mathrm{m} /$ and the alveolar approximant $/ \mathrm{r} /$ mirrors the movement of a gaping fish mouth. Jason creates his own intimate characterisation of the speech impairment, using markers of the generic aspect: the indefinite article "a" and unanchored simple present tense. For Pierre-Louis Patoine, abstract descriptions (philosophical as well as psychological) tend to create a distance between the work and the reader, stopping the reader from feeling overwhelmed (see Patoine 2015). Here, in spite of the use of the universal aspect of the sentence, this description is very concrete and personal, which is why it elicits a physical reaction within the reader.

This emphasis on physicality in Jason's "complex revised understanding" (Toolan 2012: 213) of the event generates what Patoine has called a "somesthesic" effect on the reader (Patoine 2015: 9). Patoine aims to study the semiotic, cognitive and neurophysiological structures that help build a mimetic relation between the real body of the reader and the bodies represented in fictional situations (ibid.: 9). The latter thus shows that while reading, comprehension and imagination provoke "ghost-like sensations" in readers (ibid.: 86). A literary work could then be conceived as some sort of simulation technology whose intensity is proportional to the empathetic link that binds us to the work. Depending on the topic and the literary devices used, somesthetic effects can be felt through different parts of the body: Patoine takes as an example the short story "Guts" by Chuck Palahniuk (Palahniuk 2005), which is likely to engage the reader's mind, heart and stomach (Patoine 2015: 165-191), and whose public readings frequently provoked nausea and fainting in the audience (ibid.: 9). Patoine's book is a descriptive endeavour as well as a prescriptive one: somesthetic sensations are part of what he calls "empathetic reading", which he defines as a reading technique, that can be worked on to improve the quality and intensity of the reading experience (ibid.: 12). It is 
to be understood as "a set of modes of reading characterised by more or less intense bodily engagement of the reader in literary fiction" (ibid.).

In this present extract, I would locate the somesthetic effects in the place of articulation: the larynx, windpipe, vocal folds, and nasal cavity are all under siege, even when reading the text silently. Indeed, Patoine analyses subvocalisation (the internal speech typically made when reading) as central to empathetic reading, leading to a communion of voices between narrator and reader. Subvocalisation is a phenomenon found mostly in readers that are faced with a word they have never encountered. That is why we are compelled to mark a pause on the words that David Mitchell makes up, such as the verb "gupper", which is duplicated to visually mimic stuttering, therefore transferring Jason's disorder to the reader. Adding to Patoine's argument, I would like to underline that empathetic reading as a technique has much to gain from the powerful practice of performing or hearing fiction, at any age. In this particular instance, whether subvocalising or reading aloud, I find myself stumbling, gasping for air, like a fish caught in a net. This empathetic reading, still according to Patoine, is to be distinguished from more intellectual approaches such as sympathy or identification (ibid.: 99-100). Experiencing first-hand the pressure of stammering on my throat, I empathise with Jason's medical and emotional trouble on a physical level.

\section{Conclusion: 'a raid on the inarticulate'}

Writing Cloud Atlas was something of a power move. But this extract will have shown, I hope, how Black Swan Green is able to move us powerfully during minor yet emotionally engaging 'accidents'. Thanks to a vivid visualisation of the traumatic moment, this text engages the reader in an empathetic and somesthetic response. In the same breath, Mitchell outlines a highly personal characterisation of a misunderstood disorder, presents himself as a smuggler of words, and celebrates his poetics of the accident.

In his conclusion to Dysfluencies: On Speech Disorders in Modern Literature, Chris Eagle addresses the "predominantly metaphorical purpose behind most literary representations of disordered speech," where speech impediments are "glorified" as a way to "disrupt language" (Eagle 2013: 159). By staying true to 
the youthful voice of his narrator, the author allows us to understand and empathise with Jason's condition and social anxiety without glorifying it. The potent yet fallible cognitive treatment of the stammer is weaved into the very fabric of the novel, so that disruptions and dislocations rarely appear contrived or overly literary.

"Words are the part of silence that can be spoken", wrote Jeanette Winterson in Lighthousekeeping (Winterson 2004: 135). At the delight and agony of the reader, this extract creates a sharp contrast between the spoken and the unspoken words. Jason's feelings of powerlessness and anxiety towards certain words are gradually overcome by his powerful storytelling. This tension is directly addressed at the end of the book, when he notes: "Words are what you fight with but what you fight about is whether or not you're afraid of them" (245). Throughout this quest for self-expression, Jason's coming of age is powered by an increasingly fearless approach to language - assertive 'raids on the inarticulate' - as Mitchell reclaims on paper all the words which would not come out. Black Swan Green does not give us a reassuring epilogue in which its young hero becomes a successful novelist like Mitchell grew up to be. What we are left with instead is the potentiality contained in repeated failure - to circle back to T.S. Eliot in his Four Quartets: "For us, there is only the trying. The rest is not our business." (Eliot 1943).

\section{References}

\section{Corpus}

Mitchell, David (2007 [2006]): Black Swan Green, New York: Random House Trade.

\section{Other works}

BBC Radio 4 (2007): "David Mitchell”, in: Bookclub, June 2007.

Begley, Adam/Mitchell, David (2010): "David Mitchell, The Art of Fiction No. 204", in: The Paris Review 193, https:/www.theparisreview.org/ interviews/6034/the-art-of-fiction-no-204-david-mitchell (Last accessed: 15.01.2020). 
Bissel, Tom (2004): "History is a nightmare", in: The New York Times, 29 August 2004, https:/www.nytimes.com/2004/08/29/books/history-is-a-nightma re.html (Last accessed: 02.07.2019).

Deleuze, Gilles (1994): "He stuttered.", in: Constantin V. Boundas/Dorothea Olkowski (eds.), Gilles Deleuze and the theater of philosophy, New York: Routledge.

Eagle, Chris (2013): Dysfluencies: On speech disorders in modern literature, Bloomsbury Publishing USA.

Eliot, Thomas S. (1943): Four quartets, New York: Harcourt.

Freudenberger, Nell (2006): 'Wonder year: 'Black Swan Green,' by David Mitchell", in: The New York Times, April 2006, https:/www.nytimes.com/ 2006/04/16/books/review/wonder-year.html (Last accessed: 15.06.2019).

Higashida, Naoki (2013): The reason I jump: The inner voice of a thirteen-year-old boy with autism, Random House.

Holcombe, Garan (2013): "David Mitchell: Critical perspective", in: British Council, https://iterature.britishcouncil.org/writer/david-mitchell (Last accessed: 16.06.2019).

Johnson, Jeffrey K. (2008): "The visualisation of the twisted tongue: Portrayals of stuttering in films, television, and comic books", in: The Journal of Popular Culture, 41 (2), 245-261.

Johnson, Wendell (1959): The Onset of Stuttering, Minneapolis \& Saint Paul: University of Minnesota Press.

Kuster, Judith Maginnis (2011): "At long last, a positive portrayal of stuttering", in: The ASHA Leader, 16 (2), 13-25, https://leader.pubs.asha.org/doi/10.104 4/leader.FTR2.16022011.13 (Last accessed: 16.01.2020).

Libby, Lisa K. et al. (2005): "Here's looking at me: The effect of memory perspective on assessments of personal change", in: Journal of Personality and Social Psychology, 88 (1), 50-62.

Mitchell, David (2004): Cloud Atlas, New York: Random House Trade.

- (2006): "Let me speak", in: The Telegraph, 30 April 2006, https://www.telegra ph.co.uk/culture/3652013/Let-me-speak.html (Last accessed: 15.06.2019).

- (2011): "Lost for words", in: Prospect Magazine, 23 February 2011, https://ww w.prospectmagazine.co.uk/magazine/david-mitchell-stammering-kings -speech (Last accessed: 12.04.21).

- (2017): "David Mitchell: What my son's autism has taught me", in: The Guardian, 8 July 2017, https://www.theguardian.com/society/2017/jul/o8/ david-mitchell-son-autism-diagnosis-advice (Last accessed: 15.06.2019). 
Mudge, Alden (2006): "David Mitchell: Seconde childhood", in: Bookpage, April 2006, https://bookpage.com/interviews/8342-david-mitchell\%23.W aiAlEpJaDU (Last accessed 12.05.2019).

Onslow, Mark (2016):Stuttering and its treatment: eleven lectures, University of Sydney.

- (2020): Stuttering and its treatment: eleven lectures, University of Sydney, htt ps://www.uts.edu.au/sites/default/files/2020-07/Stuttering\%20and\%20i ts\%20Treatment-Eleven\%20Lectures\%20\%28May\%202020\%29.pdf (Last accessed: 06.03.2021).

Palahniuk, Chuck (2005): "Guts”, in: Chuck Palahniuk, Haunted, New York: Anchor Books, 12-21.

Patoine, Pierre-Louis (2015): Corps/texte: pour une théorie de la lecture empathique. Cooper, Danielewski, Frey, Palahniuk, Lyon: ENS Éditions.

Smith, Ali (2006): "Neither sweet nor as simple", in: The Telegraph, 14 May 2006, https://www.telegraph.co.uk/culture/books/3652162/Neither-sweet -nor-as-simple.html (Last accessed: 02.06.2019).

Tisdale, Sallie (2013): "Voice of the voiceless", in: The New York Times, $23 \mathrm{Au}$ gust 2013, https://www.nytimes.com/2013/08/25/books/review/the-reaso n-i-jump-by-naoki-higashida.html (Last accessed: 13.05.2019).

Toolan, Michael (2012): "Engagement via emotional heightening in 'Passion': On the grammatical texture of emotionally-immersive passages in short fiction", in: The Ohio State University Press, 20 (2), 210-225.

Tykwer, Tom at al. (2012): Cloud Atlas, Warner Bros.

Urban Dictionary (2021): 'pinch', https://www.urbandictionary.com/define.p hp?term=pinch (Last accessed 18.04.2021).

Winterson, Jeanette (2004): Lighthousekeeping, New York: Fourth Estate/Harper Collins Publishers LLC. 